\title{
Effectiveness of iron supplementation in the perioperative management of total knee arthroplasty: a systematic review
}

\author{
Seung Hoon Lee ${ }^{1}$, Joong II Kim², Wonchul Choi ${ }^{3}$, Tae Woo Kim ${ }^{4}$ and Yong Seuk Lee ${ }^{5^{*}}$
}

\begin{abstract}
Introduction/purpose: The purpose of this systematic review was to evaluate the effect of iron supplementation during total knee arthroplasty (TKA): (1) Is the iron supplementation necessary during TKA? (2) When is the optimal timing of iron supplementation? (3) Which is better, between orally and intravenously administered iron supplementation? And (4) What is the optimal dose of iron supplementation?

Materials and methods: A rigorous and systematic approach was used and each of the selected studies was evaluated for methodological quality. Data about study design, total number of cases enrolled, iron administration method, timing, and dose were extracted. Change in hemoglobin and transfusion rates were extracted to evaluate the effectiveness of iron supplementation.

Results: Eleven studies were included in the final analysis. Most of studies reported that hemoglobin change between iron and control group did not show any difference. Only one study reported that iron supplementation could reduce the decrease in hemoglobin. However, transfusion rate showed a decrease in the iron supplementation group compared with the control group. There was no clear consensus on the optimum timing and dose of iron supplementation and intravenously administered iron was more effective than orally administered iron, especially in anemic patients.

Conclusion: Iron supplementation is not clear as a way to raise hemoglobin levels after TKA, but an effective treatment for lowering transfusion rate, especially in patients with anemia. We could not determine the optimal timing and dose of the iron. Intravenously administered iron was similar to, or better than, orally administered iron for improving hemoglobin levels and transfusion rate.
\end{abstract}

Keywords: Total knee arthroplasty, Transfusion, Iron supplement, Hemoglobin, Iron

\section{Introduction}

Total joint arthroplasty (TJA) is a successful and costeffective treatment option for end-stage osteoarthritis (OA) [1]. However, TJA is an invasive procedure that can cause serious complications, such as blood loss, which is a major concern. Despite numerous studies on blood loss and its management during TJA, but there is

\footnotetext{
*Correspondence: smcos1@hanmail.net

${ }^{5}$ Department of Orthopaedic Surgery, Seoul National University College of Medicine, Bundang Hospital, Seoul, South Korea

Full list of author information is available at the end of the article
}

little consensus about the amount of blood loss and management strategies for reducing the blood loss. This gap in our knowledge could be the differences in characteristics of the patient groups, surgical method, or the method used for the estimation of blood loss. Although there may be differences in blood loss, the decrease of hemoglobin after TKA is about $3 \mathrm{~g} / \mathrm{dL}$ [2]. This often leads to allogenic transfusion, from $3 \%$ up to $69 \%[3,4]$. THA is associated with a higher transfusion rate than TKA [5]. THA is usually performed to treat hip fracture, whereas TKA is performed as a regular operation. There

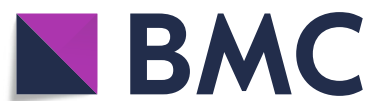

Part of Springer Nature (c) The Author(s). 2020 Open Access This article is licensed under a Creative Commons Attribution 4.0 International License, which permits use, sharing, adaptation, distribution and reproduction in any medium or format, as long as you give appropriate credit to the original author(s) and the source, provide a link to the Creative Commons licence, and indicate if changes were made. The images or other third party material in this article are included in the article's Creative Commons licence, unless indicated otherwise in a credit line to the material. If material is not included in the article's Creative Commons licence and your intended use is not permitted by statutory regulation or exceeds the permitted use, you will need to obtain permission directly from the copyright holder. To view a copy of this licence, visit http://creativecommons.org/licenses/by/4.0/. The Creative Commons Public Domain Dedication waiver (http://creativecommons.org/publicdomain/zero/1.0/) applies to the data made available in this article, unless otherwise stated in a credit line to the data. 
are more opportunities to improve the hemoglobin levels in the case of TKA, and the epidemiology of the patients who undergo TKA is also different from that of patients undergoing THA.

Allogenic transfusion can lead to increased length of stay, perioperative infection, and increased cost of treatment. Many methods have been tried to reduce allogenic transfusion, such as oral and intravenous administration of tranexamic acid, or intra-articular or subcutaneous routes to reduce transfusion rate [6-9]. The auto-transfusion system is a method that reduces allogenic transfusion during TKA [10]. Erythropoietin is also used to reduce the transfusion rate without adverse effects [11]. However, it is impossible to predict the exact effect of these methods, as they have been selected according to the needs of each patient, under different conditions [12-15].

Iron supplementation is widely accepted as an effective method for treatment of anemia during surgery. Iron can be administered orally or intravenously and is also available in high and low doses as per the requirement. There is little consensus regarding the method and optimal dose of iron supplementation. Iron supplementation can be used easily with few adverse effects, and it is also cost-effective [16]. Therefore, it can be a useful tool for perioperative blood management of TKA. Some metaanalyses have also reported the use of iron supplementation during various surgeries [17-19]. As blood loss can be different for each operation or surgical method, it is difficult to formulate a consistent conclusion after analyzing these heterogeneous surgical methods using pooled analysis. Instead, analysis should be performed individually for each surgical method. We believe that a separate analysis of the perioperative blood management in TKA is necessary.

The purpose of this study was to analyze the perioperative blood management in TKA. We included studies that compared the effect of iron supplementation under the conditions similar to those seen in TKA. We also wanted to evaluate the effect of iron supplementation in the perioperative blood management of TKA. Our systematic review was conducted to answer the following questions by analyzing studies that assessed iron supplementation for the perioperative blood management of TKA: (1) Is the iron supplementation necessary during TKA? (2) When is the optimal timing of iron supplementation? (3) Which is better, between orally and intravenously administered iron supplementation? And (4) What is the optimal dose of iron supplementation?

\section{Material and methods}

\section{Search strategy}

Rigorous and systematic approach conforming to the Preferred Reporting Items for Systematic review and Meta-Analysis (PRISMA) guidelines was used to verify our research question [20]. In phase 1 of the PRISMA search process, selected databases, including MEDLINE, EMBASE, and Cochrane database were searched (31 March 2020). A Boolean strategy was used, and all field search terms included the following: Search ([lower limb arthroplasty] OR [total knee arthroplasty]) AND ([iron] OR [ferric] OR [ferrous]). The references in the included studies were also screened, and unpolished articles were also checked manually. The bibliographies of the relevant articles were subsequently cross-checked for articles not identified in the search. In phase 2 , abstracts and titles were screened for relevance. In phase 3 , the full text of the selected studies was reviewed according to the inclusion criteria, and methodological appropriateness was determined with a predetermined question. In phase 4, the studies were subjected to an appropriate systematic review process.

\section{Eligible criteria}

The following eligibility criteria were used to select studies: (1) the articles should be about TKA, (2) the articles should be written in English, (3) the full text of the article should be available, (4) the articles should include human in-vivo studies, and (5) the articles should include comparative studies about the use of iron use. The exclusion criteria were as follows: (1) articles not related to TKA, (2) articles including studies about perioperative blood management with selective iron use, (3) articles published before 2000, and (4) articles that were not clinical studies (experimental or review article).

\section{Data assessment}

Each of the selected studies was evaluated by two independent authors for methodological quality. Data were extracted by the following standardized protocol: publication year, publication journal, study type, number of cases, type of iron supplement, timing, and dose of iron supplement, change in the levels of hemoglobin, serum ferritin and transferrin saturation, and transfusion rate. The extracted data were then cross-checked for accuracy and any disagreement were settled by the third contributing author. To assess the methodological quality of the studies, quality assessment was conducted using the Modified Coleman Criteria (Appendix A) [21]. The Modified Coleman Criteria has a scaled potential score ranging from 0 to 100 . Scores of $85-100$ are excellent, $70-84$ are good, $55-69$ are fair, and scores $<55$ are poor. It is used for assessing the quality of surgical studies. Part A includes study size, mean follow-up, type of study, and diagnostic certainty. Part B includes outcome criteria, procedure for assessing clinical outcomes, description of patient selection process, post-operative rehabilitation, surgical technique, complications recorded, 
and revisions recorded. These criteria were created by two authors to quantify the quality of studies.

\section{Results \\ Search}

Eleven articles were included in the final analysis. Seven randomized controlled trials (RCTs) [22-28], one prospective cohort study [29], and three retrospective cohort studies [30-32] were included for the final analysis. Two of them were studies with conflict of interest [23, 32]. The PRISMA flow chart is shown in Fig. 1.

\section{Quality}

All articles underwent quality assessment using the Modified Coleman Criteria [21]. Included studies and modified Coleman Criteria Scoring are presented in Table 1 . The studies that we analyzed had an average modified Coleman Criteria Score of 59.5, and eight studies were fair whereas three studies were poor. Most studies compared more than 50 cases and seven studies were RCTs. However, the timing of post-operative hemoglobin measurement was different (1 day to 6 weeks post operation) for each study, and there were differences in indications for allogenic transfusion (hemoglobin $<7 \mathrm{~g} / \mathrm{dL}$ to $<9 \mathrm{~g} / \mathrm{dL}$ ) as shown in Tables 2 and 3. Quality of the studies was satisfactory.

\section{Effectiveness of iron supplementation}

Effectiveness of iron supplementation was evaluated using nine articles that performed case-control comparison (Table 3) [24-32]. Among them, five articles used intravenously administered iron supplementation $[25,26,30-32]$, three used orally administered iron supplementation [24, 27, 28], and one selectively used intravenously or orally administered iron supplementation according to the level of serum ferritin [29]. In each study, the effect of iron supplementation was compared by comparing change in hemoglobin level and transfusion rate after surgery. Among nine studies, one reported significant increase in hemoglobin levels in the iron supplementation group when compared to that seen in the control group, until 6 weeks after the surgery [25]. This study used intravenously administered iron (iron sucrose), along with recombinant human erythropoietin. No significant difference in hemoglobin levels was seen between the iron supplementation group and the control group in the remaining eight studies (Table 3 ).

Seven studies reported transfusion rate which is shown in Fig. 2 [24-26, 29-32]. Figure 2 also include one another study that reported transfusion rates by iron administration method [23]. Among them, two RCTs reported that iron supplementation did not lower transfusion rates, but other five studies reported lowered transfusion rates when compared with those of the control group. Five studies were conducted in patients with anemia (hemoglobin 10 to $13 \mathrm{~g} / \mathrm{dL}$ or 1 -day postoperative hemoglobin $<10 \mathrm{~g} / \mathrm{dL}$ ) [25, 26, 30-32]. One study reported that hemoglobin was higher in the iron supplementation group when compared with that of the control group [25], and four studies reported that iron

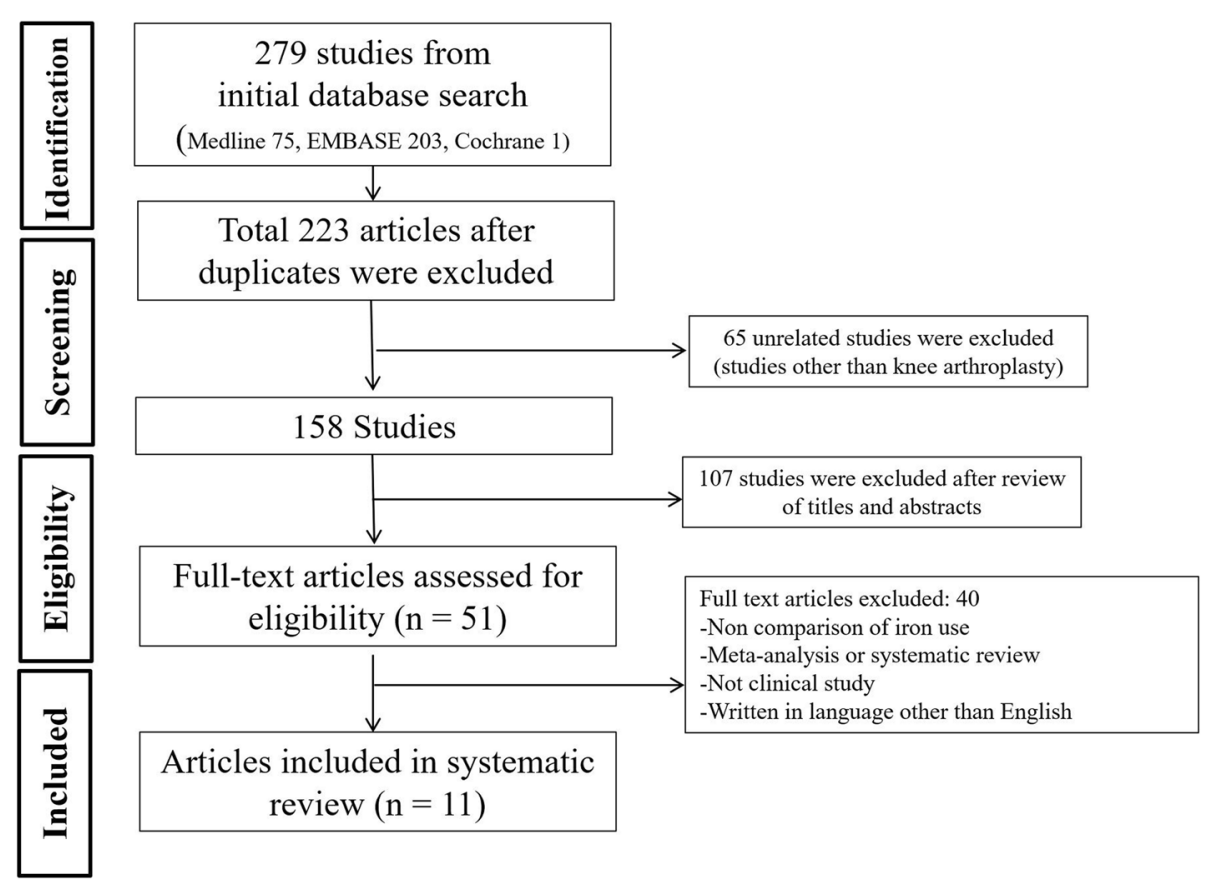

Fig. 1 Preferred Reporting Items for Systematic review and Meta-Analysis (PRISMA) flow chart 
Table 1 Quality of included studies

\begin{tabular}{|c|c|c|c|c|c|}
\hline Author & Journal & Year & Modified Coleman A score & Modified Coleman B score & Modified Coleman Total score \\
\hline Park et al. [26] & J Clin Med & 2019 & 27 & 34 & 61 \\
\hline Heschl et al. [30] & Eur J Anaesthesiol & 2018 & 20 & 32 & 52 \\
\hline Biboulet et al. [22] & Anesthesiology & 2018 & 27 & 37 & 64 \\
\hline Bisbe et al. [23] & $\mathrm{Br} J$ Anaesth & 2014 & 30 & 37 & 67 \\
\hline Muñoz et al. [31] & Blood transfus & 2014 & 20 & 32 & 52 \\
\hline Muñoz et al. [32] & Br J Anaesth & 2012 & 20 & 32 & 52 \\
\hline Na et al. [25] & Transfusion & 2011 & 30 & 34 & 64 \\
\hline Gonzalez-Porras et al. [29] & Transfus Med & 2009 & 27 & 32 & 59 \\
\hline Mundy et al. [24] & JBJS & 2005 & 27 & 34 & 61 \\
\hline Sutton et al. [27] & JBJS & 2004 & 27 & 34 & 61 \\
\hline Weatherall et al. [28] & ANZ J Surg & 2004 & 27 & 34 & 61 \\
\hline
\end{tabular}

supplementation was effective in lowering the transfusion rate $[25,30-32]$. Another study reported that iron supplementation lowered the transfusion rate and increased iron availability, although the increase was not statistically significant [26].

\section{Timing of iron supplementation}

Iron supplementation was used preoperatively in three studies, post-operatively in six, intraoperatively in one, and used together in one study during intraoperative and post-operative period [25]. Among them, the study that used iron supplementation together in intraoperative and post-operative period reported an increase in hemoglobin levels, when compared with those of control group. Iron supplement was effective in five studies for lowering transfusion rate (two studies that used iron supplementation preoperatively $[29,30]$, two that used iron supplementation post-operatively and one that used iron supplementation intraoperatively and postoperatively [25]). However, optimal timing of the iron supplement was not evaluated in any of these studies.

\section{Method of iron administration: orally and intravenously}

Three studies compared the efficiency of orally and intravenously administered iron supplementation (Table 4). Two of those studies were RCTs and one was a prospective cohort study [29]. One study reported that intravenous administration of iron supplementation significantly increased hemoglobin levels when compared with those seen in the oral administration of iron supplementation [22], but other studies reported that there was no difference in hemoglobin levels between the two groups, but intravenous administration was more effective in increasing iron availability [23]. In patients with hemoglobin levels $<10 \mathrm{~g} / \mathrm{dL}$, intravenous administration significantly increased hemoglobin levels compared to the orally administered supplementation group [23]. Transfusion rates were also compared in two studies, but no differences were reported between the two groups [23, 29].

\section{Dose of iron supplementation}

Only one study compared the effect of iron supplementation dose [32]. In this study, no difference was seen in the increase in hemoglobin levels corresponding to the iron dose, but the transfusion rate was low in the highdose iron supplementation group (200 $\mathrm{mg}$ iron sucrose for 3 days or $600 \mathrm{mg}$ ferric carboxymaltose) when compared with those seen in the low-dose iron supplementation group (100 mg iron sucrose for 3 days).

\section{Discussion}

This systematic review was performed to answer following questions: (1) Is the iron supplementation necessary during TKA? (2) When is the optimal timing of iron supplementation? (3) Which is better, between orally and intravenously administered iron supplementation? And (4) What is the optimal dose of iron supplementation? Eleven articles were finally included and used for answering these questions. We observed that iron supplementation can help in the treatment of post-operative anemia and lower the transfusion rate, especially in patients who have preoperative anemia. We could not determine the optimal timing for the administration of iron supplementation. Intravenous administration of iron was more effective than oral administration and a high dose of iron was more effective than a lower dose. Most of the included studies stated that iron supplementation has negligible effect on the hemoglobin level, but a confirmative effect on the transfusion rate. However, we believe that it is necessary to consider the time points at which the hemoglobin level was checked.

Recently, a meta-analysis reported the effect of iron supplementation in surgical patients. A meta-analysis by Shin et al. [17] reported that intravenously administered iron supplementation significantly reduces the proportion of 


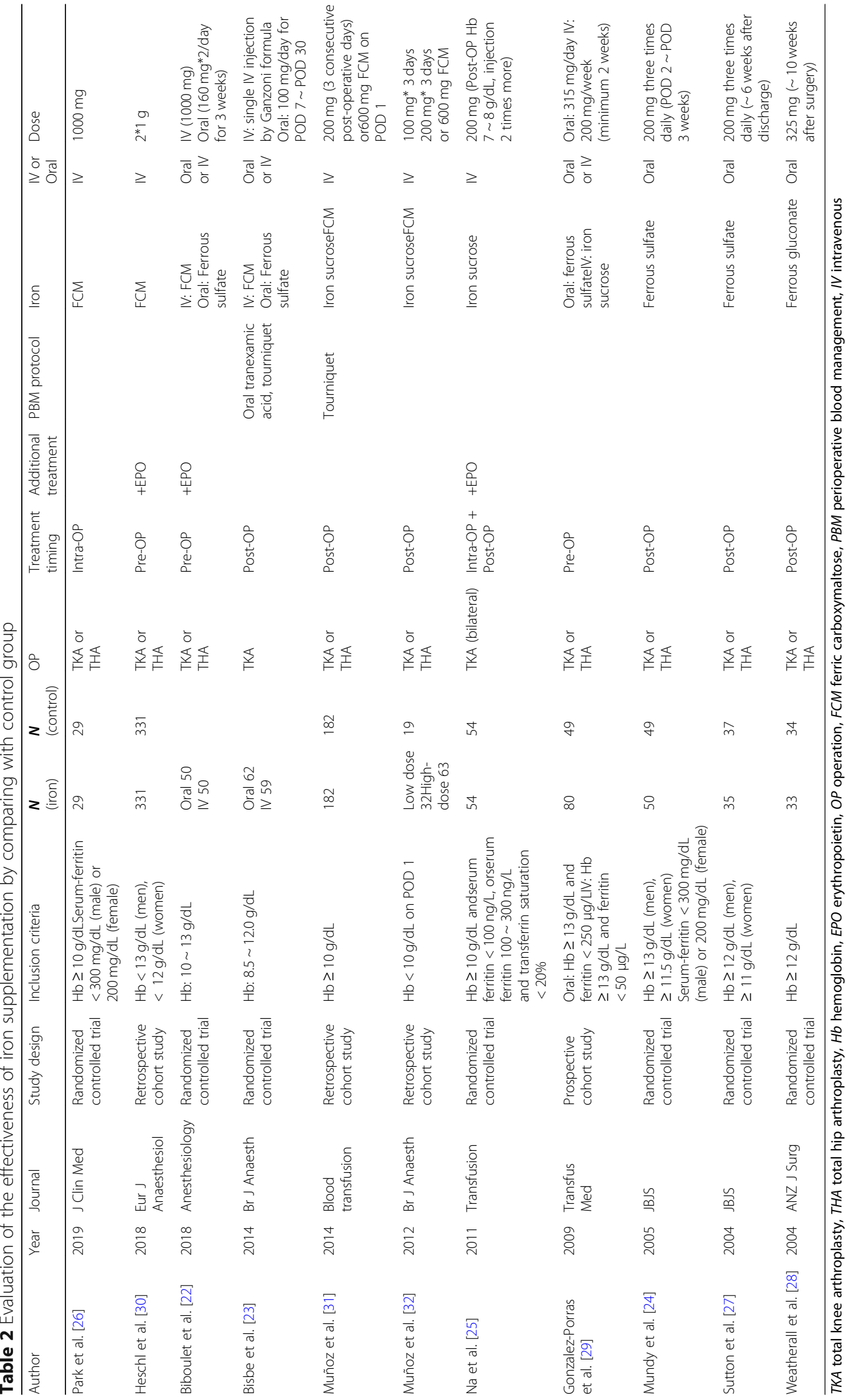




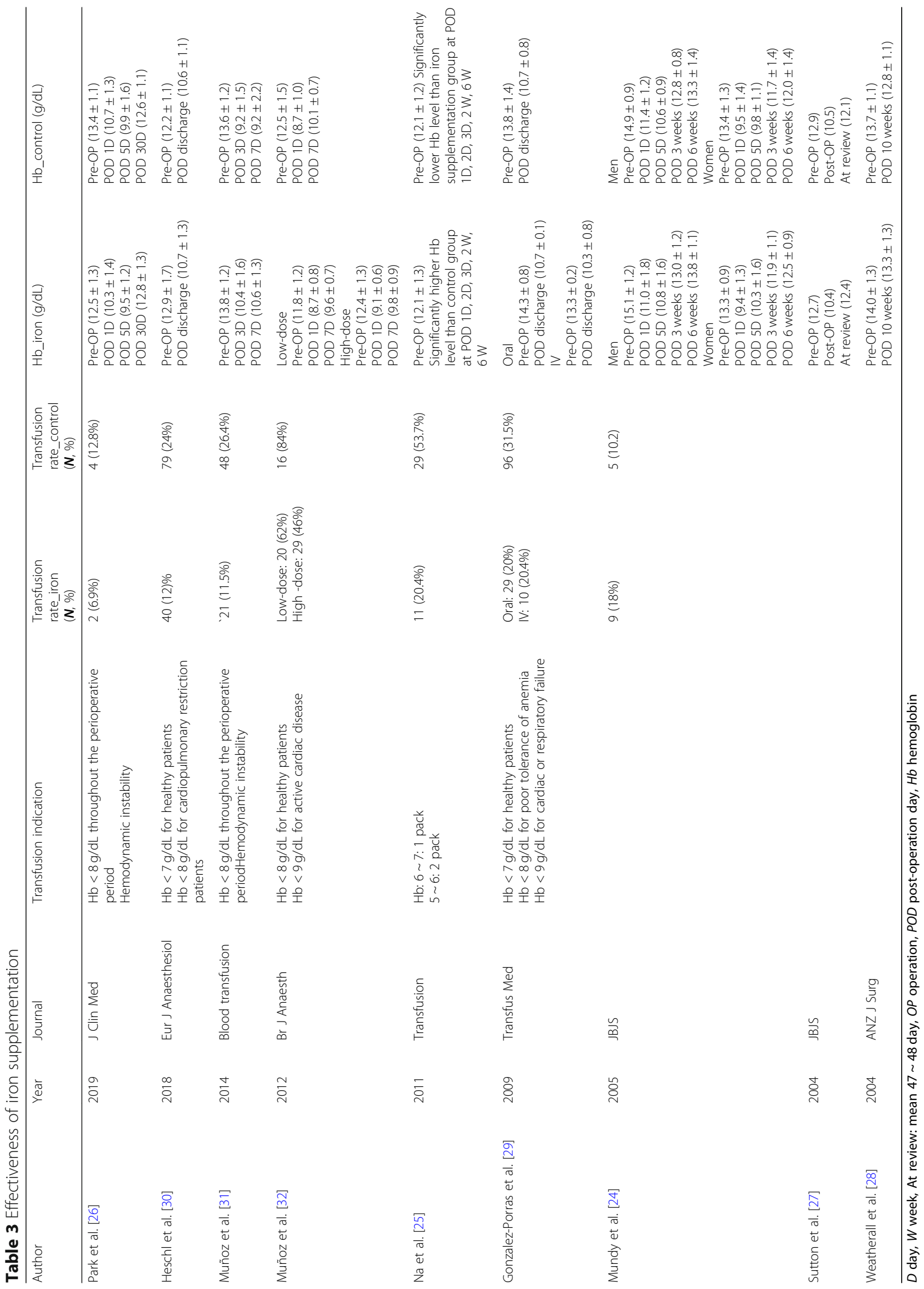




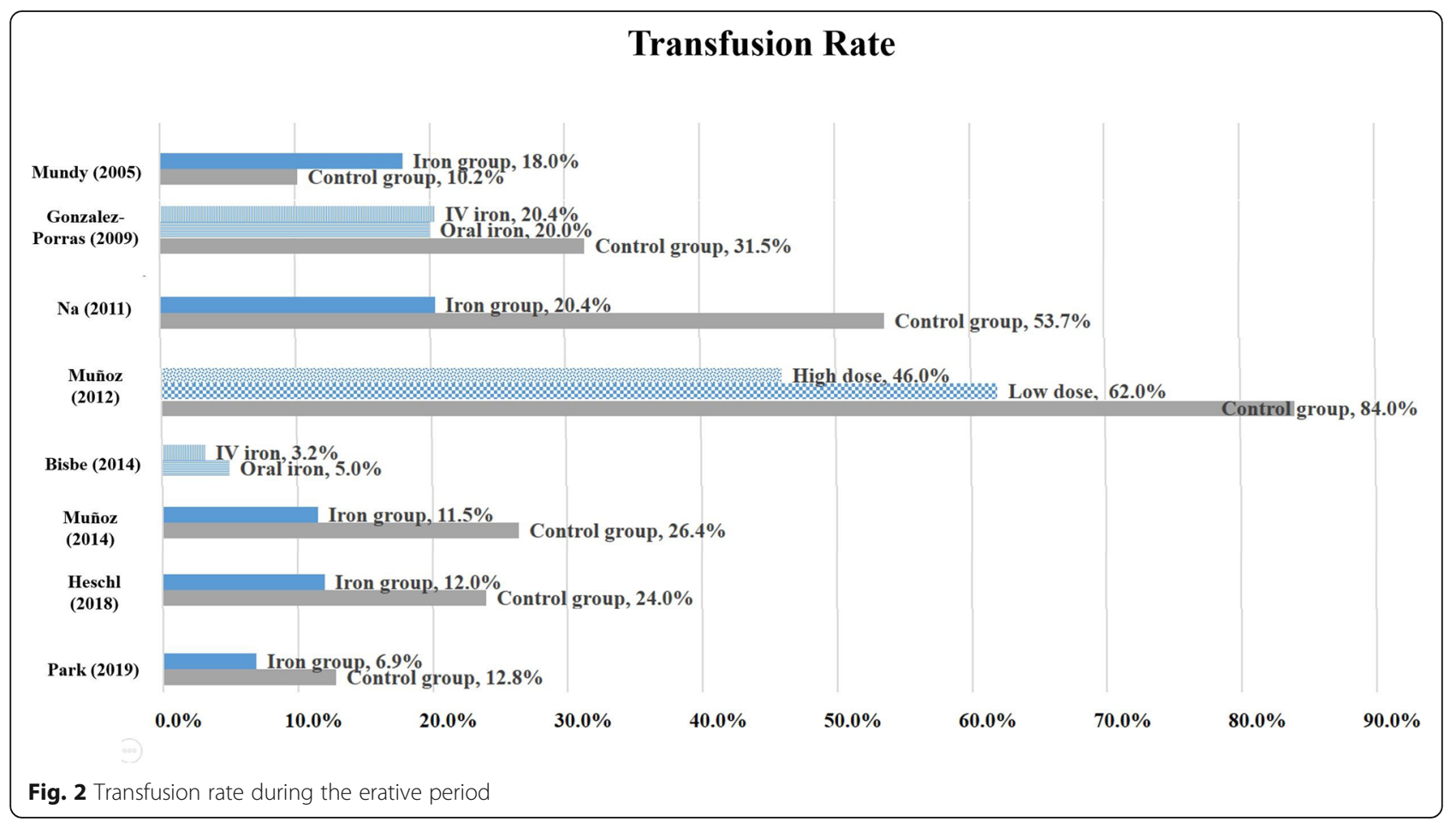

transfusion and shortens the length of hospital stay in orthopedic surgery. However, a meta-analysis by Koo et al. [18] reported that while intravenously administered iron supplementation may increase the post-operative hemoglobin level, transfusion rates cannot be reduced in surgical patients. A meta-analysis by Yang et al. [19] reported that iron supplementation raises the hemoglobin level but does not affect the transfusion rate. However, these studies were performed in different conditions and it is difficult to compare blood loss directly due to the differences in the amount of bleeding. Additionally, indications of the transfusion could also be different, and even for the same operation, the amount of blood loss varies according to the surgical method and technique of the surgeon. Therefore, only comparative studies such as ours can assess the efficacy of the iron supplementation.

Intravenously administered iron supplementation was a similar or superior method for increasing hemoglobin levels and lowering transfusion rate compared to orally administered iron supplementation. However, a high intravenously administered iron dose (ferric carboxymaltose) was used in two studies [22, 23], and a low intravenously administered iron dose was used (iron sucrose) in one study [29], so it is thought that there was an effect according to the administration dose as well as the administration method. A meta-analysis by $\mathrm{Koo}$ et al. [18] reported that intravenously administered iron was better for increasing hemoglobin levels than orally

Table 4 Effectiveness of iron supplementation according to the route of administration

\begin{tabular}{|c|c|c|c|c|c|c|c|}
\hline Author & Year & Journal & Transfusion indication & $\begin{array}{l}\text { Transfusion } \\
\text { rate_IV } \\
(\boldsymbol{N}, \%)\end{array}$ & $\begin{array}{l}\text { Transfusion } \\
\text { rate_Oral } \\
(\boldsymbol{N}, \%)\end{array}$ & $\mathrm{Hb} \_\mathrm{IV}(\mathrm{g} / \mathrm{dL})$ & Hb_Oral (g/dL) \\
\hline Biboulet et al. [22] & 2018 & Anesthesiology & & & & $\begin{array}{l}\text { Pre-OP }(14.9) \\
\text { POD 1D (12.6) } \\
\text { POD 3D (12.6) } \\
\text { POD 5D (13.4) }\end{array}$ & $\begin{array}{l}\text { Pre-OP (13.9) } \\
\text { POD 1D (12.2) } \\
\text { POD 3D (11.6) } \\
\text { POD 5D (12.3) }\end{array}$ \\
\hline Bisbe et al. [23] & 2014 & Br J Anaesth & $\begin{array}{l}\mathrm{Hb}<8 \mathrm{~g} / \mathrm{dL} \text { or acute anemia } \\
\text { symptoms }\end{array}$ & $3(5 \%)$ & $2(3.2 \%)$ & $\begin{array}{l}\text { Pre-OP }(13.6 \pm 0.9) \\
\text { POD 1D }(10.5 \pm 1.0) \\
\text { POD 4D }(9.7 \pm 1.3) \\
\text { POD 30D }(11.5 \pm 1.2)\end{array}$ & $\begin{array}{l}\text { Pre-OP }(13.6 \pm 0.9) \\
\text { POD 1D }(10.5 \pm 1.0) \\
\text { POD 4D }(9.7 \pm 1.1) \\
\text { POD 30D }(11.0 \pm 1.1)\end{array}$ \\
\hline $\begin{array}{l}\text { Gonzalez-Porras } \\
\text { et al. [29] }\end{array}$ & 2009 & Transfus Med & $\begin{array}{l}\mathrm{Hb}<7 \mathrm{~g} / \mathrm{dL} \text { for healthy patients } \\
\mathrm{Hb}<8 \mathrm{~g} / \mathrm{dL} \text { for poor tolerance of } \\
\text { anemiaHb }<9 \mathrm{~g} / \mathrm{dL} \text { for cardiac or } \\
\text { respiratory failure }\end{array}$ & $10(20.4 \%)$ & $29(20 \%)$ & $\begin{array}{l}\text { Pre-OP }(13.3 \pm 0.2) \\
\text { POD discharge } \\
(10.3 \pm 0.8)\end{array}$ & $\begin{array}{l}\text { Pre-OP }(14.3 \pm 0.8) \\
\text { POD discharge } \\
(10.7 \pm 0.1)\end{array}$ \\
\hline
\end{tabular}


administered iron, but both methods affected the transfusion rate in a similar manner. As very few studies compared the timing of iron supplementation, we could not determine the optimum timing for the administration of iron supplementation. However, as it is widely believed that hemoglobin level rises in 2 to 4 weeks after iron supplementation, surgeons should consider this for determining the optimum timing for the administration iron supplementation [33]. A meta-analysis by Shin et al. [17] reported that iron dose does not affect the transfusion rate. In our analysis, a high dose of iron lowered the transfusion rate. As there was only one study on iron dose, we believe that this could be insufficient evidence to draw any conclusion about the iron dose.

Iron supplementation often translates into additional costs for patients. Considering the increase in length of stay and the cost of transfusion, iron supplementation could be cost-effective, although direct comparison has not been performed $[31,34]$. However, the cost can differ according to each country's health care system and insurance status, and it may not be available in some countries. It has also been reported that the use of iron supplementation can reduce the length of hospital stay $[35,36]$. Therefore, further studies are necessary to evaluate the effects and possible complications of iron supplementation when compared with the transfusion, and determine its optimal form, dose, and timing. Moreover, we believe that RCTs that are identical in terms of the type, dose, and timing of the iron supplementation are necessary. Additionally, studies that accurately measure blood loss, hemoglobin levels, ferritin levels and its saturation rate at regular time intervals are also necessary.

The present study also has some limitations. First, only one of the included studies was conducted with unilateral TKA alone, whereas the rest of the studies included bilateral TKA or THA. This may have influenced the results of our study due to the difference in the amount of blood that was lost. Second, iron type, dose, timing, and indication of iron supplementation were not identical in all the studies, and the time point of hemoglobin-level estimation was also different. Therefore, we decided to perform systematic review than meta-analysis. Third, the publication years of the included studies were also different. With the current advancement of iron formulations, recent studies have shown favorable results for iron supplementation, with a distinct possibility of improvement in future. Fourth, in some studies, other formulations were also used along with iron supplementation for reducing blood loss, such as tranexamic acid and erythropoietin.

\section{Conclusion}

Iron supplementation is not clear as a way to raise hemoglobin after TKA, but an effective treatment for lowering transfusion rate, especially in patients with preoperative anemia. We could not determine the optimal timing and dose of the iron. Intravenously administered iron was similar to, or better than, orally administered iron for improving hemoglobin levels and transfusion rates.

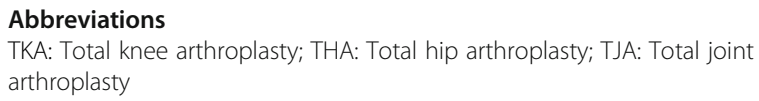

\section{Acknowledgements}

Not applicable

\section{Authors' contributions}

KJI, KTW, CHC: substantial contribution to conception and study design. LYS, LSH: data collection, data analysis, revising the draft critically, and final approval of the version. The author(s) read and approved the final manuscript.

\section{Funding}

There was no funding source.

\section{Availability of data and materials}

All data generated or analyzed during this study are included in this published article.

\section{Ethics approval and consent to participate}

This is a systematic review article and Institutional Review Board approval was waived.

\section{Consent for publication}

Not applicable

\section{Competing interests}

The authors declare that they have no competing interests.

\section{Author details}

${ }^{1}$ Department of Orthopaedic Surgery, Veterans Health Service Medical Center, Seoul, South Korea. ${ }^{2}$ Department of Orthopaedic Surgery, Hallym University Kangnam Sacred Heart Hospital, Seoul, South Korea. ${ }^{3}$ Department of Orthopaedic Surgery, CHA University, CHA Bundang Medical Center, Seongnam-si, South Korea. ${ }^{4}$ Department of Orthopaedic Surgery, Seoul Metropolitan Government-Seoul National University Boramae Medical Center, Seoul, South Korea. ${ }^{5}$ Department of Orthopaedic Surgery, Seoul National University College of Medicine, Bundang Hospital, Seoul, South Korea.

Received: 28 May 2020 Accepted: 13 August 2020

Published online: 28 August 2020

\section{References}

1. Jones CA, Beaupre LA, Johnston DW, Suarez-Almazor ME (2005) Total joint arthroplasties: current concepts of patient outcomes after surgery. Clin Geriatr Med 21:527-541 vi

2. Park JH, Rasouli MR, Mortazavi SM, Tokarski AT, Maltenfort MG, Parvizi J (2013) Predictors of perioperative blood loss in total joint arthroplasty. J Bone Joint Surg Am 95:1777-1783

3. Spahn DR, Moch H, Hofmann A, Isbister JP (2008) Patient blood management: the pragmatic solution for the problems with blood transfusions. Anesthesiology 109:951-953

4. Kimball CC, Nichols Cl, Vose JG (2019) Blood transfusion trends in primary and revision total joint arthroplasty: recent declines are not shared equally. J Am Acad Orthop Surg 27:e920-e927

5. Menendez ME, Lu N, Huybrechts KF, Ring D, Barnes CL, Ladha K, Bateman BT (2016) Variation in use of blood transfusion in primary total hip and knee arthroplasties. J Arthroplast 31:2757-2763.e2752

6. Seol YJ, Seon JK, Lee SH, Jin C, Prakash J, Park YJ, Song E (2016) Effect of tranexamic acid on blood loss and blood transfusion reduction after total knee arthroplasty. Knee Surg Relat Res 28:188-193

7. Kim DH, Lee GC, Lee SH, Pak CH, Park SH, Jung S (2016) Comparison of blood loss between neutral drainage with tranexamic acid and negative 
pressure drainage without tranexamic acid following primary total knee arthroplasty. Knee Surg Relat Res 28:194-200

8. Perreault RE, Fournier CA, Mattingly DA, Junghans RP, Talmo CT (2017) Oral tranexamic acid reduces transfusions in total knee arthroplasty. J Arthroplast 32:2990-2994

9. Lee QJ, Ching WY, Wong YC (2017) Blood sparing efficacy of oral tranexamic acid in primary total knee arthroplasty: a randomized controlled trial. Knee Surg Relat Res 29:57-62

10. Pawaskar A, Salunke AA, Kekatpure A, Chen Y, Nambi GI, Tan J, Sonawane D, Pathak S (2017) Do autologous blood transfusion systems reduce allogeneic blood transfusion in total knee arthroplasty? Knee Surg Sports Traumatol Arthrosc 25:2957-2966

11. Li Y, Yin P, Lv H, Meng Y, Zhang L, Tang P (2018) A meta-analysis and systematic review evaluating the use of erythropoietin in total hip and knee arthroplasty. Ther Clin Risk Manag 14:1191-1204

12. Kurian DJ, Guinn NR, Hunting J, Gamble JF, Hopkins TJ, Grimsley A, Guercio JR, Bolognesi MP, Schroeder R, Aronson S (2019) Preoperative blood management strategy for elective hip and knee arthroplasty. J Healthc Qual 41:376-383

13. Kopanidis P, Hardidge A, McNicol L, Tay S, McCall P, Weinberg L (2016) Perioperative blood management programme reduces the use of allogenic blood transfusion in patients undergoing total hip and knee arthroplasty. J Orthop Surg Res 11:28

14. Frew N, Alexander D, Hood J, Acornley A (2016) Impact of a blood management protocol on transfusion rates and outcomes following total hip and knee arthroplasty. Ann R Coll Surg Engl 98:380-386

15. Lee QJ, Mak WP, Yeung ST, Wong YC, Wai YL (2015) Blood management protocol for total knee arthroplasty to reduce blood wastage and unnecessary transfusion. J Orthop Surg 23:66-70

16. Liumbruno GM, Grazzini G (2014) Double bull's eye for post-operative intravenous iron in patient blood management: better outcome and costeffective. Blood Transfus 12:7-9

17. Shin HW, Park JJ, Kim HJ, You HS, Choi SU, Lee MJ (2019) Efficacy of perioperative intravenous iron therapy for transfusion in orthopedic surgery: a systematic review and meta-analysis. PLoS One 14:e0215427

18. Koo CH, Shin HJ, Cho H, Ryu JH (2020) The effect of perioperative intravenous iron on hemoglobin in surgical patients: a meta-analysis. J Surg Res 246:42-51

19. Yang $Y$, Li H, Li B, Wang $Y$, Jiang $S$, Jiang $L$ (2011) Efficacy and safety of iron supplementation for the elderly patients undergoing hip or knee surgery: a meta-analysis of randomized controlled trials. J Surg Res 171:e201-e207

20. Moher D, Liberati A, Tetzlaff J, Altman DG (2009) Preferred reporting items for systematic reviews and meta-analyses: the PRISMA Statement. J Clin Epidemiol 62:1006-1012

21. Aujla RS, Esler CN (2017) Total knee arthroplasty for osteoarthritis in patients less than fifty-five years of age: a systematic review. J Arthroplast 32:25982603.e2591

22. Biboulet $P$, Bringuier $S$, Smilevitch $P$, Loupec $T$, Thuile $C$, Pencole M, Maissiat G, Dangelser G, Capdevila X (2018) Preoperative epoetin-alpha with intravenous or oral iron for major orthopedic surgery: a randomized controlled trial. Anesthesiology 129:710-720

23. Bisbe E, Molto L, Arroyo R, Muniesa JM, Tejero M (2014) Randomized trial comparing ferric carboxymaltose vs oral ferrous glycine sulphate for postoperative anaemia after total knee arthroplasty. Br J Anaesth 113:402409

24. Mundy GM, Birtwistle SJ, Power RA (2005) The effect of iron supplementation on the level of haemoglobin after lower limb arthroplasty. J Bone Joint Surg (Br) 87:213-217

25. Na HS, Shin SY, Hwang JY, Jeon YT, Kim CS, Do SH (2011) Effects of intravenous iron combined with low-dose recombinant human erythropoietin on transfusion requirements in iron-deficient patients undergoing bilateral total knee replacement arthroplasty. Transfusion 51: 118-124

26. Park HS, Kim TY, Kim HJ, Ro YJ, Jang HY, Koh WU (2019) The effect of intraoperative ferric carboxymaltose in joint arthroplasty patients: a randomized trial. J Clin Med 8:1674

27. Sutton PM, Cresswell T, Livesey JP, Speed K, Bagga T (2004) Treatment of anaemia after joint replacement. A double-blind, randomised, controlled trial of ferrous sulphate versus placebo. J Bone Joint Surg (Br) 86:31-33

28. Weatherall M, Maling TJ (2004) Oral iron therapy for anaemia after orthopaedic surgery: randomized clinical trial. ANZ J Surg 74:1049-1051
29. Gonzalez-Porras JR, Colado E, Conde MP, Lopez T, Nieto MJ, Corral M (2009) An individualized pre-operative blood saving protocol can increase preoperative haemoglobin levels and reduce the need for transfusion in elective total hip or knee arthroplasty. Transfus Med 19:35-42

30. Heschl M, Gombotz H, Haslinger-Eisterer B, Hofmann A, Bohler N, Meier J (2018) The efficacy of pre-operative preparation with intravenous iron and/ or erythropoietin in anaemic patients undergoing orthopaedic surgery: an observational study. Eur J Anaesthesiol 35:289-297

31. Munoz M, Gomez-Ramirez S, Martin-Montanez E, Naveira E, Seara J, Pavia J (2014) Cost of post-operative intravenous iron therapy in total lower limb arthroplasty: a retrospective, matched cohort study. Blood Transfus 12:40-49

32. Munoz M, Naveira E, Seara J, Cordero J (2012) Effects of postoperative intravenous iron on transfusion requirements after lower limb arthroplasty. Br J Anaesth 108:532-534

33. Alleyne M, Horne MK, Miller JL (2008) Individualized treatment for irondeficiency anemia in adults. Am J Med 121:943-948

34. Basora M, Pereira A, Coca M, Tio M, Lozano L (2018) Cost-effectiveness analysis of ferric carboxymaltose in pre-operative haemoglobin optimisation in patients undergoing primary knee arthroplasty. Blood Transfus 16:438442

35. Kotze A, Carter LA, Scally AJ (2012) Effect of a patient blood management programme on preoperative anaemia, transfusion rate, and outcome after primary hip or knee arthroplasty: a quality improvement cycle. Br J Anaesth 108:943-952

36. Kim SK, Seo WY, Kim HJ, Yoo JJ (2018) Postoperative intravenous ferric carboxymaltose reduces transfusion amounts after orthopedic hip surgery. Clin Orthop Surg 10:20-25

\section{Publisher's Note}

Springer Nature remains neutral with regard to jurisdictional claims in published maps and institutional affiliations.
Ready to submit your research? Choose BMC and benefit from:
- fast, convenient online submission
- thorough peer review by experienced researchers in your field
- rapid publication on acceptance
- support for research data, including large and complex data types
- gold Open Access which fosters wider collaboration and increased citations
- maximum visibility for your research: over $100 \mathrm{M}$ website views per year
At BMC, research is always in progress.
Learn more biomedcentral.com/submissions 